evidence for $H$. rudolfensis at Olduvai is central to the taxonomic argument because the type specimen of $H$. habilis is a juvenile mandible and skull, $\mathrm{OH} 7$, from Olduvai. So the species group that includes $\mathrm{OH} 7$ must carry the name $H$. habilis. The suite of morphological differences that distinguish $H$. rudolfensis from $H$. habilis sensu stricto are functionally coherent and include a flatter, broader face and broader postcanine teeth with more complex crowns and roots and thicker enamel. Although $H$. rudolfensis crania are generally larger than those of $H$. habilis sensu stricto, the differences in overall size are a minor component of what is otherwise an impressive suite of morphological distinctions.

The same morphological evidence has been read differently by others and $\mathrm{OH} 7$ judged to be distinct from the remaining non-australopithecine cranial evidence from Bed I and Lower Bed II of Olduvai Gorge $^{6,7}$. This results in an alternative taxonomy, with KNM-ER 1470 and 1802 joining $\mathrm{OH} 7$ in $\mathrm{H}$. habilis sensu stricto and KNM-ER 1813, together with $\mathrm{OH} 16$ and 24 , belonging to a second, unnamed, early Homo species. Schrenk et al. apparently accept the former taxonomic analysis at Olduvai and assign UR 501 to $H$. rudolfensis because of its resemblances to KNM-ER 1802 from Koobi Fora.

That said, the importance of UR 501 is threefold. First, its discovery supports the idea that at least one other hominid genus, in the form of $H$. rudolfensis, has paralleled Paranthropus in developing a morphology of its face, jaws and teeth which places emphasis on a capacity for chewing.

Second, together with the morphologically more tenuous evidence from Chemeron $^{8}$, UR 501 suggests that $H$. rudolfensis arose as early as 2.5-2.4 Myr. This date coincides with what had been interpreted as an abrupt change in the global $^{9}$, and particularly African ${ }^{10}$, climate from a warmer, moister regime to a colder and more arid one. But the move to increased aridity may have been a slower, incremental, process which began at around $3 \mathrm{Myr}$ and continued through to 2 Myr (ref. 11). So attempts to correlate the evolution of African mammals with external climatic influences no longer have to demonstrate a strict 2.5 Myr synchronicity. Nonetheless, the Uraha evidence suggests that if increased emphasis on chewing was occurring in two hominid lineages, then the first appearances of the taxa involved, $P$. aethiopicus and $H$. rudolfensis, are both dated at around 2.5 Myr (ref. 12)

Third, the identification of UR 501 as $H$. rudolfensis, reinforces evidence from other large-mammal groups in Unit 3A that the Malawi faunas have stronger links with East Africa than with sites of similar age in southern Africa. From comparison of the mammalian faunas from the two regions, Turner and myself ${ }^{13}$ concluded that between $4 \mathrm{Myr}$ ago and now there have been both movements of fauna between the two regions as well as dispersions in common to them.

Schrenk et al. argue that the 'window' that Unit 3A provides onto faunal exchange implies that at around 2.4 Myr the predominant movement was from the southern to the eastern region. They infer this because, of the faunal elements from the Malawi site, more originated in the southern than in the eastern region. And they suggest that this ties in with the climate becoming more arid resulting in the Equatorward drift of the habitats which are then tracked by many mammals, particularly bovids. But first appearances of fossil taxa are a notoriously fickle tool to use to compare two regions with temporally discontinuous samples from different time ranges. The authors interpret the absence of $H$. rudolfensis from southern Africa as further evidence that evolutionary events were mainly occurring in the environments of East Africa where tropical forest and woodlands persisted, even during periods of relative aridity.

The special significance of the new discoveries is that they furnish evidence about the dynamics of the faunal interchanges between the two main African regions that have yielded early hominids. With analyses of deep-sea cores providing more precise records of past climates, evidence from sites such as Karonga and Uraha will lead to a better appreciation of the ways mammalian groups have responded to climatic fluctuations ${ }^{14}$. In particular we can hope for clarification of the relationships between the hominid fossil records of the two regions, and a better understanding of why hominid lineages responded in the ways they did to the climatic challenges of the Late Pliocene. $\square$

Bernard Wood is in the Department of Human Anatomy and Cell Biology, University of Liverpool, Liverpool L69 3BX. UK.

\footnotetext{
Schrenk, F., Bromage, T. G., Betzler, C. G. \& Ring, U. Nature 365, 833-836 (1993)

2. Senut, B., Pickford. M. Ssemmanda. I., Elepu. D. \& Obwona. P. C. r. hebd. Séanc. Acad. Sci., Paris 305 , 819-822 (1991).

3. Pickford. M. Senut, B. Poupeau, G., Brown, F. H. \& Haileab. B. C. r. hebd Séanc. Acad. Sci., Paris 313, 223-229 (1991)

223-229(1991). M. Meyer, C. E., Roth, P. H. \& Brown. Sarna-Wojcicki, A. M., Meyer, C. E.,
F. H. Nature 313, 306-308 (1985)

5. Wood, B. A. Nature 355, 783-790 (1992)

6. Stringer. C. B. in Major Topics in Primate and Human Evolution (eds Wood, B., Martin, L. \& Andrews, P. 266-294 (Cambridge University Press, 1986)

Rightmire. G. P. Am. J phys. Anthropol 90, 1-33 Rightmire,

(1993)

8. Hill, A., Ward, S., Deino, A.. Curtis, G. \& Drake, R. Nature 355, 719-722 (1992)

9. Shackleton, N. J. Nature 307,620-623 (1984)

10. Vrba, E. S., Burckle, L. H., Denton, G. H. \& Partridge, T. C. (eds) S. Afr. J. Sci. 81, 224-275 (1985)

11. Raymo M.E. Hodell, D. \& Jansen, E. Paleoceanography 7, 645-672 (1992)

12. Walker A Leakey, R. E Harris, J.M \& Brown, F. H. Nature 322, 517-522 (1986).

13. Turner. A. \&Wood. B. A. J. hum. Evol. 24, 147 (1993)

14. Vrba, E. S. J.Mammal. 73, 1-28 (1992)
}

\section{Safe passage}

TELEPHONES, broadcast receivers, datalinks and modems have no memory. If you do not catch and store a message at once, it is gone for good. So Daedalus proposes a cable which, on the 'bucket brigade' principle of bubble memories and charge-coupled devices, combines transmission and storage. You feed data into it like marbles into a pipe, and they shuttle along to the other end. If the flow is interrupted, the data stay safely where they are until it resumes.

Daedalus's pipe will be one of those zeolite solid-state electrolytes through which ions can flow freely, and its marbles will be packets of ions. Such flowing ions should form a sort of onedimensional micro-liquid; they must tend to spread out by mutual repulsion so the liquid will be compressible. DREADCO's chemists are seeking sets of contrasting ions which form mutually immiscible micro-liquids. Injected into the cable by pulsed electrodes, they will travel along its molecular channels as a stable sequence of packets, without mixing. All the usual packet-switching technology would work on this cable. At the far end, each ion-packet will be decoded by its characteristic deposition-voltage.

Ionic cable thus combines delay-line memory and digital transmission. Ions can be fired almost losslessly through a crystal lattice at many kilometres a second, so transmission could be almost electronically fast. But by broadening the cable at its ends, the ionic packets could be slowed to a relative amble. The resulting ion-reservoirs could hold many minutes or hours of compressed traffic.

Communications will be transformed. When the computer-net goes down, no information will vanish. It will merely sit in the wires, and start moving again when they are reconnected. Similarly, a message transmitted to an inactive telephone will no longer be lost, but will simply build up in the wire. Pick up the phone; the ions will resume their march and you will hear the stored message. Switch off the TV, and incoming programmes will build up in the downlead. Yoù could let them out at your leisure, and at any rate you chose. In fast-forward mode the compressed ionic traffic would emerge at high speed; it could be throttled back for real-time viewing, or released in single-picture bursts for freeze-frame display. You could even push it back into the wire, and watch it emerge again. Video recorders, E-mail terminals, faxes, answering machines, all the complex data-traps of modern communications, will be replaced by the electronic equivalent of letters landing on the doormat, to be read at your leisure.

David Jones 